\title{
A análise de sonhos nas terapias cognitivas e comportamentais
}

\section{Dream analysis in cognitive and behavior therapies}

\author{
LUC VANDENBERGHE \\ Artur Vandré PITANGA'
}

\begin{abstract}
Resumo
A análise dos sonhos acompanha a psicoterapia desde o início, sendo, inclusive, a primeira mais antiga do que a segunda. A terapia cognitiva de Beck como também diferentes vertentes da terapia comportamental supõem que o sonho esclareça aspectos das vivências acordadas do paciente. Tanto a tradição cognitiva quanto a comportamental propõem estratégias para aproveitar essa suposta continuidade entre as vivências acordadas e o sonho. As práticas da análise de sonhos são altamente semelhantes nos dois estilos terapêuticos. A diferença fundamental reside nos pressupostos de causalidade: problemas do cotidiano e produção de sonhos são atribuídos a contingências pelos terapeutas comportamentais e a estruturas e processos mentais pelos terapeutas cognitivos.
\end{abstract}

Unitermos: análise funcional; análise do sonho; terapia cognitiva; terapia comportamental.

\begin{abstract}
Dream analysis has followed psychotherapy from its early beginnings. In fact it is older than psychotherapy. Both Beck's cognitive therapy and different streams within behavioral therapy suppose that dreams clarify aspects of the dreamer's daily life. Both the cognitive and the behavioral traditions propose strategies to use this hypothesized continuity between woken life and dream. The practices of dream analysis are highly similar in the two therapeutic styles. The fundamental difference resides in the causal theories: Daily life problems and dream production are attributed by behavioral authors to contingencies and by cognitive therapists to mental structures and processes.
\end{abstract}

Uniterms: functional analysis; dream analysis; cognitive therapy; behavior therapy.

A natureza dos sonhos é uma questão antiga. Uma pergunta que deve interessar ao psicoterapeuta é se o sonho é produto de processos psicológicos mundanos ou tem origens particulares que não estão ao alcance da ciência profana. A questão pode ser resumida nos termos continuidade versus descontinuidade entre a vivência do sonho e as vivências acordadas. Continuidade significa que os fatores importantes para entender a vida do cotidiano estarão também em jogo no sonho. Descontinuidade significa, nesse caso, que se trata de dois mundos diferentes. Essa questão diz respeito, de um lado, à possibilidade de interpretações místicas do conteúdo do sonho e, de outro, à viabilidade de aproveitar essa análise para

$\operatorname{coth}$

1 Universidade Católica de Goiás, Departamento de Psicologia. 5 a Avenida, Setor Universitário, Goiânia, GO, Brasil. Correspondência para/Correspondence to: L.VANDENBERGUE. E-mail:<luc.m.vandenberghe@gmail.com>. 
entender algo sobre os processos psicológicos das vivências acordadas da pessoa que sonha.

Já na Antigüidade havia autores que consideravam os sonhos como fenômenos naturais presentes na continuidade das vivências acordadas, enquanto outros consideravam que os sonhos eram qualitativamente diferentes dos fenômenos das vivências acordadas. Aristóteles (de 384 a 322 a.C.) propôs que sonhar é uma atividade mental normal durante o sono e que os sonhos são produtos dos mesmos processos psicológicos como a imaginação, o pensamento e a lembrança. O estudo dessa atividade pressupõe, de acordo com ele, os mesmos princípios do estudo da percepção acordada e das alucinações. É interessante que por causa dessa continuidade entre o sonho e as atividades das vivências acordadas, o estudo dos sonhos deve dar acesso aos mesmos processos que também estão por trás dessas experiências. A análise dos sonhos pode assim revelar mecanismos que subjazem à vivência do indivíduo no seu cotidiano (Aristóteles, 2001).

Quinhentos anos depois da obra de Aristóteles, Aristemidoro (1990) argumenta a favor de uma visão contrária: os sonhos têm uma natureza diferente da percepção e da imaginação acordada. Segundo esse autor, eles revelam o futuro e o passado, sendo eles a expressão de um mundo sobrenatural.

Essas duas opiniões podem ser reconhecidas nas posições de autores que estavam no berço das psicoterapias. Freud (de 1856 a 1939) propôs que o sonho reflete conteúdos individuais da pessoa que sonha, geralmente tratando-se da satisfação de desejos ou expressões de pulsões reprimidas. Além disso, ele afirma que os sonhos são construídos a partir da experiência da vida do cotidiano. Sempre contêm referências ao dia passado e todas as falas significativas são provenientes de falas que a pessoa que sonha ouviu ou leu durante o dia (Freud, 1900/1996).

Diferentemente, seu contemporâneo mais jovem, Jung (de 1875 a 1961), distinguiu entre sonhos insignificantes que trabalham problemas do cotidiano e sonhos significativos que são um caminho de transmissão da sabedoria milenar da humanidade. Esses últimos trazem símbolos que, independentes das narrativas tecidas ao redor deles pela pessoa que sonha, têm uma vida própria por serem produtos espontâneos

240 do inconsciente coletivo. Enquanto o inconsciente pessoal é o resultado da vivência do indivíduo, os conteúdos do inconsciente coletivo não foram adquiridos durante a vida individual (Jung, 1943/1975).

A posição freudiana enfatiza o significado pessoal do sonho, o que acarreta a possibilidade de conhecer, através da análise do sonho, aspectos das dinâmicas psicológicas do paciente, abrindo caminho para esclarecer o que está por trás dos sintomas das vivências acordadas. Os sonhos pós-traumáticos, como também os sonhos que no decorrer de uma psicanálise trazem lembranças de traumas infantis, revelam tentativas inconscientes de dominar conteúdos ameaçadores (Freud, 1920/1974).

Porém o conteúdo manifesto da maioria dos sonhos disfarça, de acordo com o autor, uma camada latente que representa a realização de desejos de quem sonha. Desejos inconscientes que não passam pela censura interior do indivíduo são transformados, deixando o conteúdo manifesto difícil de reconhecer. Na sessão, o método de associação livre, instrumento típico da psicanálise, possibilita o acesso ao conteúdo latente. A análise dos sonhos pode assim oferecer uma via real para os conteúdos do inconsciente (Freud, 1920/1974).

Para Jung (1943/1974) um sonho significante pode ser reconhecido pela presença de arquétipos. Essa presença indica que o mesmo pretende comunicar algo fundamental, algo que transcende as limitações do indivíduo. $\mathrm{O}$ autor descreve sonhos de repetição que tentam tornar consciente uma condição psíquica particularmente problemática e geralmente também trazem uma proposta de solução. Em sonhos compensatórios aspectos de arquétipos que não são bem desenvolvidos na vida do cotidiano da pessoa que sonha são expressos.

Quando a pessoa vivencia suas experiências cotidianas de forma excessivamente unilateral, seu sonho pode até criar, para compensar os déficits, um mundo completamente oposto. Além disso, há sonhos que predizem o futuro ou contêm uma advertência para um perigo futuro. Às vezes esses sonhos pretendem sinalizar para a pessoa que ela precisa mudar seu estilo de vida ou fazer uma determinada escolha para evitar uma catástrofe futura. Para interpretar os sonhos, não se depende, como é o caso no método freudiano, das associações altamente pessoais do paciente, mas 
procuram-se referências nos mitos antigos, na arte e em outras fontes que podem elucidar os arquétipos.

Percebemos que enquanto a análise de sonhos encontrou um lugar de destaque nas psicoterapias da primeira geração, já havia compreensões divergentes acerca do significado do sonho e o que ele pode acrescentar ao trabalho clínico. Este artigo pretende descrever essa prática em duas tradições psicoterápicas mais recentes: as terapias cognitivas e comportamentais.

\section{Análise de sonhos na terapia cognitiva}

Logo no início da terapia cognitiva, foi observado que os temas dos sonhos de um paciente são pertinentes para entender seus padrões comportamentais observáveis quando acordado. Os temas dos sonhos são análogos aos conteúdos com os quais o paciente sofre quando acordado (Beck, 1967). Houve tentativas de relacionar padrões de sonhos a categorias diagnósticas. Por exemplo: seqüências dos sonhos com temas de perseguição e abuso injustificado seriam típicos de pacientes com traços paranóicos (Beck, 1971).

Pacientes depressivos relataram numa pesquisa eventos desagradáveis em que eram vítimas de experiências como rejeição ou abandono. Eles contaram sonhos nos quais eles fracassaram, nos quais não conseguiam fazer o que queriam e nos quais a imperfeição, a perda, a injustiça e o futuro negro eram os temas de destaque (Beck \& Hurvich, 1959).

Porém a terapia cognitiva tem pouco interesse por essa possibilidade. Muito mais importante é o pressuposto de que relatos de sonhos contêm necessariamente informação valiosa sobre os processos cognitivos que participaram da sua gênese. Beck (1971) enfatiza que os sonhos de cada pessoa são idiossincráticos, típicos da maneira de funcionar de cada um e que seguem os mesmos processos pelos quais pensamentos automáticos e distorções cognitivas são produzidos durante o estado acordado. Por conseqüência, examinar os sonhos dos pacientes e considerar as interpretações que eles fazem é uma maneira econômica de descobrir esquemas disfuncionais.

O autor considera que os sonhos são fortemente relacionados com os temas das vivências acordadas e que podem trazer elementos importantes que permitem o estudo dos transtornos psicológicos. São produtos do mundo interior da pessoa que sonha. Isso garante uma coerência entre o sonho e os processos cognitivos durante as vivências acordadas. É importante destacar que ele descreve os sonhos como expressões temáticas das cognições dos pacientes e não como conteúdos manifestos que devem ser interpretados e decodificados para alcançar o significado mais profundo.

Freeman e Bayll (1992) também enfatizam que os sonhos devem ser compreendidos em termos dos temas e do contexto de vida e não como termos simbólicos. O conteúdo temático dos sonhos deve ser relacionado diretamente às preocupações do cotidiano do paciente. A linguagem específica e as imagens de um sonho são importantes para sua compreensão, como também as respostas emocionais do paciente às mesmas. Felicidade, ansiedade, tristeza têm os mesmos efeitos para o paciente tanto no sonho quanto quando acordado. As durações particulares de outros aspectos formais de elementos do sonho são menos importantes já que uma imagem que apareça durante só um momento pode possuir um enorme impacto emocional que pode trazer muita informação importante quando questionada na terapia.

A pessoa que sonha não é um observador passivo. Ela participa ativamente na integração da explosão caótica do material visual com informação emocionalmente carregada proveniente dos temas de sua vida. Dessa forma, ela ativamente dramatiza as crenças sobre si mesma, sobre o mundo e sobre o futuro. Por isso, o material do sonho reflete os conteúdos dessa tríade cognitiva, e contém as distorções cognitivas nesses três domínios. O terapeuta cognitivo tipicamente procura identificar os padrões cognitivos próprios ao paciente que são ativados durante as vivências do cotidiano.

Porém esses padrões podem ser altamente velados pelas características da situação real, tornando difícil reconhecer o que é a contribuição própria do paciente. Durante o sono influências do mundo externo são cortadas e por conseqüência os esquemas do indivíduo podem determinar de uma maneira muito mais exclusiva o conteúdo temático dos sonhos. Os pensamentos do dia-a-dia são menos diretamente ligados aos esquemas do que os sonhos, porque os últimos não são influenciados diretamente pelas restrições do mundo material (Beck, 1971). 
O sonho é um produto da pessoa que sonha, o material particular que ela introduz no seu sonho vem de suas experiências precedentes e das suas crenças atuais. Por isso, o material do sonho pode ser usado nas mesmas intervenções de reestruturação cognitiva como os pensamentos automáticos. Utilizando o registro dos pensamentos disfuncionais, o paciente pode aprender a analisar e discutir os temas disfuncionais expressos nos sonhos e modificar sua reação emocional em relação ao sonho.

Os sonhos também podem ser utilizados quando o paciente chegou a um bloqueio na terapia, quando ele não consegue mais trazer material para ser analisado e não consegue colaborar mais na análise dos conteúdos das vivências acordadas (Freeman \& Bayll, 1992).

Um ponto importante é que o próprio paciente deve interpretar seus sonhos. De acordo com o princípio do trabalho colaborativo, que é essencial na terapia cognitiva, o terapeuta tem um papel de guia que acompanha e não de um perito que conhece os sentidos dos sonhos (Freeman \& Bayll, 1992). Os processos cognitivos utilizados pelo paciente para lembrar e interpretar os detalhes do sonho necessariamente contêm as mesmas distorções que o paciente utiliza habitualmente para interpretar sua realidade exterior. Assim os sonhos oferecem poderosas metáforas para as crenças irracionais. $\mathrm{E}$ às vezes tais crenças não poderiam ter sido ativadas de maneira tão direta por um outro procedimento que pela análise dos sonhos (Beck, 1971).

Os relatos de sonhos normalmente são tratados somente como uma parte da agenda de uma sessão, porém eles têm várias vantagens na terapia cognitiva. Permite aos pacientes ter um papel criativo durante a exploração dos conteúdos e entender o seu sentido, e a partir daí conhecer e reconhecer certas crenças fundamentais e distorções cognitivas que influenciam seu cotidiano (Beck, 1971).

O paciente pode aprender a identificar uma lição no conteúdo do sonho, que o pode ajudar nos problemas do cotidiano. Alternativamente, ele pode encontrar certos momentos e imagens no sonho que Ihe trazem inspiração para descrever possíveis experiências futuras. O terapeuta pode também solicitar que o paciente anote diariamente os sonhos que se lembra, e as imagens que deles provêm podem servir como material durante a sessão (Freeman \& Bayll, 1992).
A idéia de Beck (1971), de que o sonho serve como atalho para descobrir os padrões cognitivos irracionais e irrealistas do paciente, foi levada por Barret (2002) para ser usada na medicina comportamental. Segundo esse último autor, a análise dos sonhos pode ajudar a identificar atitudes do paciente que são relevantes para identificar certos sintomas físicos. Ele discute que a análise dos sonhos pode ser valiosa como via de acesso aos conteúdos cognitivos em casos em que a comunicação direta é difícil. Isso pode ser o caso quando o paciente tem pouca compreensão das suas próprias atitudes, quando tem pouca disposição para se abrir ao terapeuta ou até quando a comunicação é dificultada por se tratar de um paciente que não pertence à mesma cultura que o terapeuta.

\section{Análise de sonhos na terapia comporta- mental}

Terapeutas comportamentais que escrevem sobre análise de sonhos muitas vezes mencionam que com essa prática não pretendem encontrar algum significado profundo. Não é a descoberta de uma resposta, mas o processo de análise que é importante para o progresso do tratamento (Callaghan, 1996; Conte, 2001; Delitti, 1999; Guilhardi, 1994). Realmente não se trata de descobrir verdades ocultas pré-existentes que esperam para ser desveladas. Uma leitura atenta desses autores deixa claro que os significados dados aos conteúdos dos sonhos são construídos durante a análise.

O uso que terapeutas comportamentais fazem dos relatos de sonhos para suas intervenções é variado. A análise de sonhos é usada na coleta de dados (diagnóstico), no processo terapêutico, e na avaliação dos efeitos da terapia (Delitti, 1993; Guihardi, 1994).

Pesquisa empírica, citada por Domhoff (2003), mostrou que atos de fala em relatos de sonhos coletados em laboratórios de sono geralmente são construções originais (e não repetições de falas que ocorreram nas vivências acordadas do participante). Essas falas são reações ao contexto dinâmico dos acontecimentos no sonho. É exatamente essa natureza espontânea que torna importantes os atos do paciente no seu sonho. A qualidade espontânea e intuitiva (quer dizer, não governada por regras, mas modelada pelas contingências) do sonho o torna uma fonte particularmente rica em dicas 
sobre as contingências importantes na vida do paciente (Vandenberghe, 2004).

A maneira como a pessoa reage ao contexto do sonho é o resultado da sua história de aprendizagem nas suas vivências acordadas. Isso é importante para o clínico porque comportamento modelado pelas contingências inevitavelmente traz informações sobre as contingências que o modelaram. Enquanto o comportamento acordado geralmente é restrito pelas contingências materiais do mundo real, o conteúdo do sonho, que não é limitado nesse sentido, mostra mais claramente o efeito das contingências passadas sobre a pessoa que sonha.

Como explicado em outro lugar (Vandenberghe, 2004), esse maior grau de liberdade na emissão de comportamentos torna a análise dos sonhos um instrumento particularmente valioso na detecção de dicas acerca das variáveis que controlam o comportamento da pessoa. Além disso, Callaghan (1996) aponta que a própria qualidade abstrata dos estímulos por si mesmo colabora para um jogo largo de comportamento verbal que ajuda o terapeuta a ter maior acesso à história de reforçamento do paciente. Isso pode proporcionar ao terapeuta oportunidades adicionais para refinar suas hipóteses sobre o comportamento do paciente e modificar adequadamente o planejamento do tratamento.

Uma outra vantagem para o uso diagnóstico é que em certos casos o paciente estará mais disposto a relatar seus sonhos do que suas vivências acordadas, porque o relato dos sonhos geralmente sofre menos censura social. Os conteúdos do sonho parecem abstratos e menos ameaçadores. Não são acontecimentos verdadeiros e a pessoa não pode se responsabilizar pela sua conduta no sonho. Por esses motivos, pacientes que têm dificuldade de admitir certos assuntos se mostram muitas vezes mais dispostos a explorar interpretações do sonho do que interpretações da sua realidade cotidiana (Delitti, 1999). A análise dos sonhos permite contornar não somente a omissão intencional de informações relevantes, mas também a esquiva não intencional de conteúdos relacionados à história passada e às contingências atuais que o paciente no seu relato da vida do cotidiano esquece ou simplesmente não identifica por serem relacionados com experiências aversivas. Assim dados importantes podem vir à luz num relato de sonhos (Conte, 2001).
Um segundo uso diz respeito ao próprio processo terapêutico. A análise do sonho pode ser um instrumento que permite ao terapeuta criar condições para que o paciente entre em contato com as contingências que são as mais relevantes em sua vida (Delitti, 1993). Exatamente essa busca do contato direto com as contingências é o cerne do trabalho terapêutico do ponto de vista behaviorista radical. Discutir os sonhos pode despertar respostas clinicamente relevantes no seio da relação terapêutica. O paciente pode ficar frustrado, com raiva, fugir da tarefa ou trazer outros padrões de comportamento problemáticos do seu cotidiano para dentro da relação terapêutica. A análise do sonho nesse caso evoca comportamentos clinicamente relevantes que podem ser analisados e trabalhados ao vivo durante a sessão. O próprio diálogo sobre o sonho é um trabalho terapêutico. Nesse processo o paciente pode, por exemplo, aprender compartilhar as suas emoções e discriminar seus próprios comportamentos encobertos (Callaghan, 1996; Delitti, 199;).

De acordo com Domhoff (2003), pesquisas empíricas documentaram que os sonhos relatados por clientes focalizam assuntos em destaque na relação terapêutica e não são, de forma alguma, uma amostra representativa dos seus sonhos. Esse dado mostra mais uma vez que os sonhos que o cliente traz para o consultório não podem ser mais do que uma fonte adicional de informação quando se trata do diagnóstico. Do outro lado, o mesmo dado fornece suporte para o uso da análise dos sonhos como técnica terapêutica no contexto do relacionamento terapeuta-cliente, como é feito particularmente na psicoterapia analítico-funcional. Quando um cliente fala de suas emoções relacionadas a algum sonho o terapeuta tem acesso imediato a um dado sobre as respostas do cliente fora da sessão e pode relacioná-lo ao que acontece no seio do relacionamento terapêutico. Uma grande variedade de comportamentos clinicamente relevantes pode ocorrer quando os clientes informam sobre seus sonhos que evocam respostas emocionais. O cliente pode tentar se esquivar do assunto, não querer responder emocionalmente, chorar na sessão, etc. A maneira como o terapeuta responderá a esses comportamentos do cliente depende do seu entendimento do caso e da pertinência desses comportamentos durante as sessões (Callaghan, 1996).

Funções mais específicas do sonho no relacionamento terapêutico são apontadas por Delitti (1999). 0 relato do sonho pode ser um recurso metafórico ou 
uma manobra de esquiva do cliente. O cliente pode contar um sonho para evitar um assunto mais aversivo na sessão ou, ao contrário, o relato de sonho pode ser exatamente a maneira com que um cliente consegue falar sobre um assunto aversivo. O relato pode ser uma expressão de um sentimento em relação ao terapeuta ou uma forma de provocar ou de testar o terapeuta sem se arriscar demais. Todos esses comportamentos podem ser clinicamente relevantes e podem possibilitar trabalho terapêutico. De maneira semelhante, Conte (2001) aponta que o terapeuta deve procurar entender funcionalmente o que o cliente relata. É necessário analisar se o relato é um mando ou um tato. O relato do sonho pode ser um comportamento verbal que descreve de maneira distorcida ou metafórica um dado importante para o desenvolvimento do tratamento ou pode ser uma maneira de exigir algo do terapeuta.

Enquanto psicoterapeutas analítico-funcionais privilegiam a oportunidade de evocar comportamentos clinicamente relevantes a fim de trabalhar ao vivo com os próprios problemas e dificuldades do cliente, Guilhardi (1994) vê na análise dos sonhos uma oportunidade de modelar intencionalmente, e em colaboração aberta com o cliente, as capacidades de auto-análise desse último. Nessa análise o cliente pode aprender a relacionar seus sentimentos, suas ações e seus sonhos com o contexto de sua vida.

Guilhardi (1994) destaca que a consciência que o cliente tem de si pode ser testada através da capacidade do cliente de fazer sentido dos seus sonhos. De um ponto de vista comportamental, ser capaz de detectar os determinantes ambientais dos seus sonhos não é outra coisa do que ser capaz de relatar as contingências do seu comportamento. Enquanto a terapia progride, deve haver uma evolução em que o conteúdo dos sonhos se torna cada vez menos misterioso para o cliente. Enquanto ele compreende melhor a relação dos seus comportamentos encobertos e suas ações com as contingências da vida dele, ele poderá melhor enfrentar os seus problemas. Assim a capacidade de interpretar os próprios sonhos pode ser uma medida do grau de consciência que o cliente tem.

\section{Discussão}

Os pressupostos da terapia cognitiva acerca do 244 assunto tratado são claros (Beck, 1967, 1971; Freeman \&
Bayll, 1992). Já que o relato de sonhos contém informações sobre os processos cognitivos que os geraram e esses são os mesmos que dão origem aos problemas do cotidiano do cliente, analisar esses relatos ajuda a descobrir os esquemas disfuncionais e distorções cognitivas que interessam ao tratamento. A forma de trabalhar também é muito direta. Com a ajuda do terapeuta, o próprio paciente interpreta seus sonhos, relacionando o conteúdo temático dos sonhos às preocupações do cotidiano do paciente.

Terapeutas comportamentais (Callaghan, 1996; Delitti, 1993; 1999; Guilhardi, 1994) usam a análise de sonhos na coleta dos dados como uma maneira de acessar e investigar os efeitos das contingências em vigor e da história de aprendizagem passada. Não se pretende encontrar nenhum significado profundo além disso.

Durante a intervenção terapêutica, a análise do sonho é um instrumento que permite ao terapeuta criar condições para que o cliente entre em contato intenso com contingências relevantes e vivencie as emoções com elas relacionadas. Essa é também uma tática para a evocação de comportamentos clinicamente relevantes, que ajuda o cliente na exploração de seus sentimentos e na discriminação de seus comportamentos encobertos. Finalmente, em todo esse processo, a análise dos sonhos é um instrumento que é útil para modelar a capacidade de auto-análise do cliente e para a avaliação dos efeitos da terapia.

O relacionamento colaborativo entre terapeuta e cliente na terapia cognitiva (Beck, 1971; Freeman \& Bayll, 1992) e na terapia comportamental (Callaghan, 1996; Guilhardi, 1994) parece muito similar. Nas duas tradições os terapeutas ajudam o cliente na forma de interpretar os sonhos, mas não acreditam ter respostas a oferecer. Percebemos que tanto a abordagem cognitiva quanto a comportamental pressupõem uma continuidade qualitativa entre as vivências acordadas e o sonho. Os sonhos possibilitam o entendimento dos padrões comportamentais do cliente quando acordado. Se o sonho fosse produto de processos diferentes dos que governam as vivências acordadas, sua análise contribuiria muito pouco.

Portanto observamos que as duas abordagens divergem quanto ao tipo de processo psicológico que 
determina nosso comportamento. Na terapia cognitiva, a temática do sonho dá acesso a esquemas cognitivos e mostra distorções que podem ser trabalhadas na sessão. Terapeutas comportamentais procuram dicas sobre as contingências atuais e históricas das quais o cliente pode não ter a mínima noção. Também usam a interpretação do sonho para avaliar e promover a consciência que o cliente pode ter do seu comportamento e das condições que o determinam. Por isso, há também dois vieses diferentes na seleção do material a ser analisado.

Terapeutas cognitivos levam o cliente a enfocar a temática do sonho, enquanto terapeutas comportamentais questionam o que a personagem da pessoa que sonha faz frente às diferentes situações com as quais o sonho a confronta. Esses dois vieses podem gerar interpretações diferentes do mesmo relato de um sonho.

Notamos que em ambas as orientações, os sonhos podem ser utilizados quando o paciente chega a um bloqueio na terapia, quando ele não consegue mais trazer material para ser analisado e não consegue colaborar mais na análise dos conteúdos das vivências acordadas (Barret, 2002; Delitti, 1999). Tal ajuda pode ser necessária quando efeitos da censura social dificultam o cliente se abrir totalmente, quando há dificuldades de comunicação ou dificuldades culturais que interferem no trabalho.

Pesquisadores que são críticos em relação ao uso de sonhos na clínica argumentam que terapeutas que afirmam manter uma posição neutra e almejam descobrir o significado verdadeiro do sonho acabam modelando as associações dos seus clientes por processos complexos de sugestão e persuasão involuntários e despercebidos (Domhoff, 2003). Mas percebemos que nem a terapia cognitiva nem a comportamental parecem cair nessa armadilha. É interessante ver que nenhuma dessas duas abordagens considera o conteúdo manifesto do sonho uma fonte de símbolos que podem ser decifrados, mas sim material para ser analisado pelo próprio cliente como atalho para a melhor compreensão dos problemas do cotidiano.

A análise dos sonhos nas terapias cognitiva e comportamental pode assim ser caracterizada por duas idéias básicas: o princípio da continuidade entre o sonho e as vivências acordadas, e o princípio que a análise dos sonhos não pode desvelar nenhuma verdade oculta ou mensagem que estava tentando se revelar à consciência.

O primeiro desses princípios mantém que sonhos e seus relatos são produtos dos mesmos processos que dominam as vivências acordadas. O segundo é resultado da noção de que a análise dos sonhos é um trabalho colaborativo em que terapeuta e cliente juntos constroem uma interpretação do sonho, relacionando-o com o cotidiano do cliente. Os resultados dessa interpretação por conseqüência não são significados que já estavam latentes no conteúdo do sonho, mas construções novas que emergiram do diálogo terapêutico.

Assim a prática da análise dos sonhos nessas duas abordagens é herdeira de uma tradição de pensamento a respeito da continuidade entre sonho e vivências acordadas, que descende pelo menos dos tempos de Aristóteles. Traz também uma visão diferente das psicoterapias tradicionais no que diz respeito à compreensão do processo interpretativo e ao papel das interpretações obtidas no tratamento.

\section{Referências}

Aristóteles (2001). Parva naturalia. Oxford: Clarendon. (Obra original do século III a. C.).

Aristemidoro, D. (1990). The interpretation of dreams: Oneirocritica. Park Ridge: Noyes. (Originalmente publicado cerca de 150 a. D.).

Barret D. (2002). The royal road becomes shrewd shortcuts: the use of dreams in focused treatment. Journal of Cognitive Psychotherapy, 1 (1), 55-63.

Beck, A. T., \& Hurvich, M. (1959). Psychological correlates of depression: Frequency of "masochistic" dream content in a private practice sample. Psychosomatic Medicine, 21 (1), 50-55.

Beck A. T. (1967). Depression: clinical experimental, and theoretical aspects. New York: Harper and Row.

Beck A. T. (1971). Cognitive patterns in dreams and daydreams. In F. H. Masserman (Org.), Dream dynamics: science and Psychoanalysis (Vol.19, pp.2-7). New York: Grune and Stratton.

Callaghan, G. M. (1996). The clinical utility of client dream report from a radical behavior perspective. The Behavior Therapist, 19 (1), 49-52.

Conte, F. (2001). A psicoterapia analítico funcional e um sonho de criança. In H. J. Guilhardi, M. Madi, P. Queiroz \& M. Scoz (Orgs.), Sobre comportamento e cognição (Vol. 6, pp.204-210). Santo André: ESETec Editores Associados.

Delitti, M. (1993). O uso de encobertos na terapia comportamental. Temas em Psicologia, 1 (2), 41-46. 
Delitti, M. (1999). Relato dos sonhos: como utiliza-los na prática da terapia comportamental. In R. C. Wielenska (Org.), Sobre comportamento e cognição (Vol. 6, pp.195-210). Santo André: ESETec Editores Associados.

Domhoff, G. W. (2003). The scientific investigation of dreams: neural networks, cognitive development, and content analysis. Washington, DC: American Psychological Association.

Freud, S. (1996). A Interpretação dos sonhos. In Edição standard das obras psicológicas completas deSigmund Freud (Vol. 5, pp.39-363). Rio de Janeiro: Imago. (Publicado originalmente em 1900).

Freud, S. (1996). Além do Princípio do Prazer. In Edição standard das obras psicológicas completas deSigmund Freud (Vol. 18, pp.17-75). Rio do Janeiro: Imago. (Publicado originalmente em 1920).

Freeman, A., \& Bayll, S. (1992). The use of dreams and the dream metaphor in cognitive behaviour therapy. Psychotherapy in Private Practice, 10 (2), 173-192.
Guilhardi, H. J. (1994). Um modelo comportamental de análise dos sonhos. In B. Rangé (Org.), Psicoterapia comportamental e cognitiva (pp.257-256). Campinas: Editora Psy.

Jung, C. G. (1975). Homem à descoberta da sua alma. Livro III: os sonhos. Porto: Tavares Martins. (Originalmente publicado em 1943).

Vandenberghe, L. (2004). Interpretar sonhos na terapia comportamental. In C. E. Costa, J. C. Luzia \& H. H. N. Sant'Anna (Orgs.), Primeiros passos em análise do comportamento e cognição (pp.105-110). Santo André: ESETec Editores Associados.

Recebido em: 27/7/2006

Versão final reapresentada em: 16/10/2006

Aprovado em: 24/11/2006 